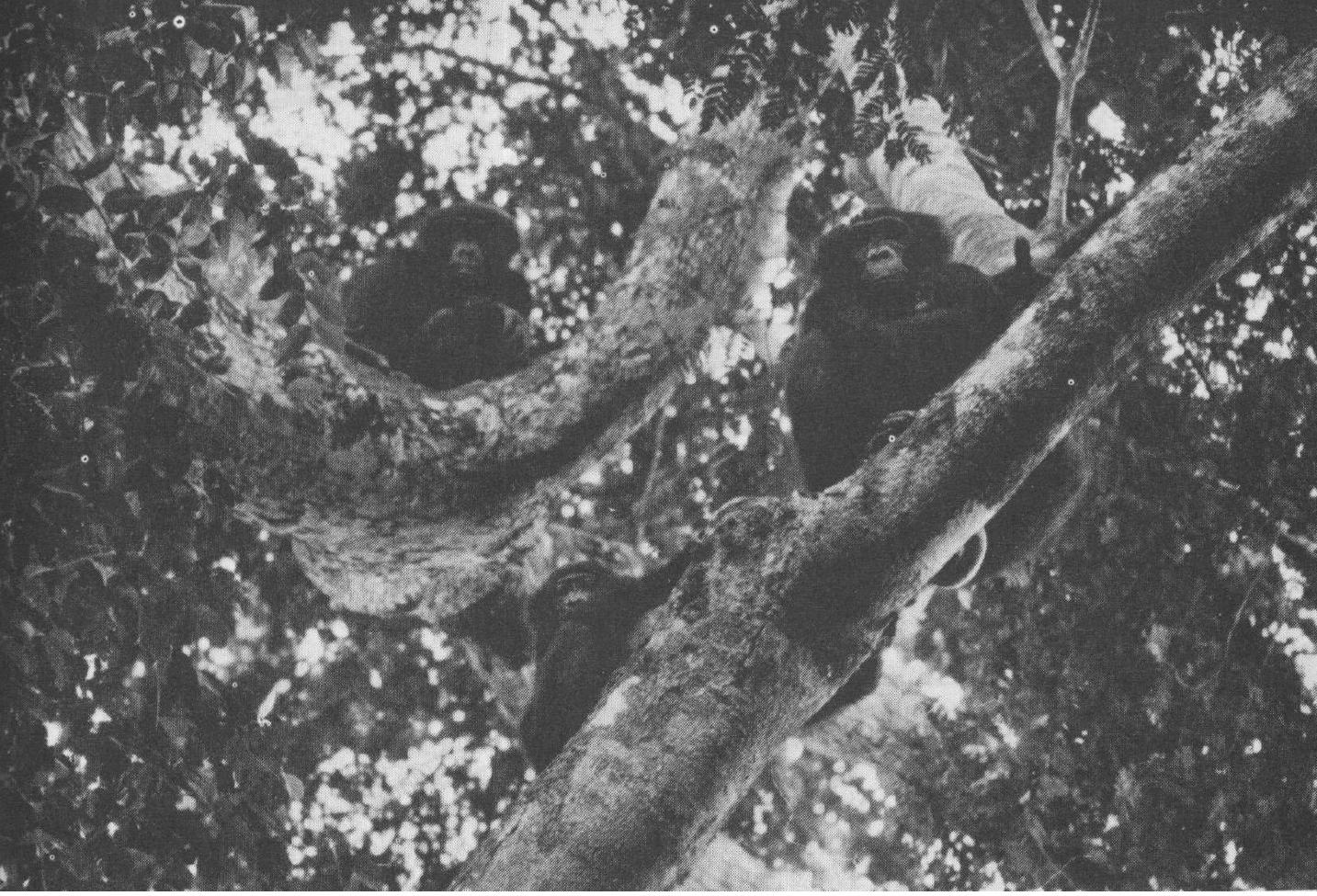

\title{
Pygmy Chimpanzees
}

\section{Alison and Noel Badrian}

Between August 1974 and July 1975 the authors spent eleven months in Zaire, six of them in an isolated tract of rain forest in the Equateur region studying the ecology and behaviour of bonobos, or pygmy chimpanzees. They urge the need to establish a reserve to protect bonobos, mainly because of threats to their habitat, and suggest an area in the Lomako Forest that is also rich in other wildlife.

The bonobo or pygmy chimpanzee was first described in 1929 by Schwarz as a new race of chimpanzee, Pan satyrus paniscus. ${ }^{9}$ After a study of museum specimens Coolidge gave them species status as Pan paniscus. ${ }^{3}$

Bonobos are small and slender, with a body weight about half that of chimpanzees. Their long, fine body hair is black except for the white circumanal tuft visible in many adults. Their heads are more rounded than the chimpanzee's, with smaller supraorbital ridges and a less developed muzzle, and the ears are smaller and almost completely covered by long, thick cheek whiskers. The hair on the crown is shorter than on the rest of the head but they have no bald patch. Even in infants all exposed skin, except the lips and the anogenital area, is black, and about half the museum specimens and zoo animals have webbing between the second and third pedal digits; this is less common among chimpanzees.

In captivity bonobos are said to be temperamentally quite different from

The photograph shows a male, a female with infant and a juvenile. 


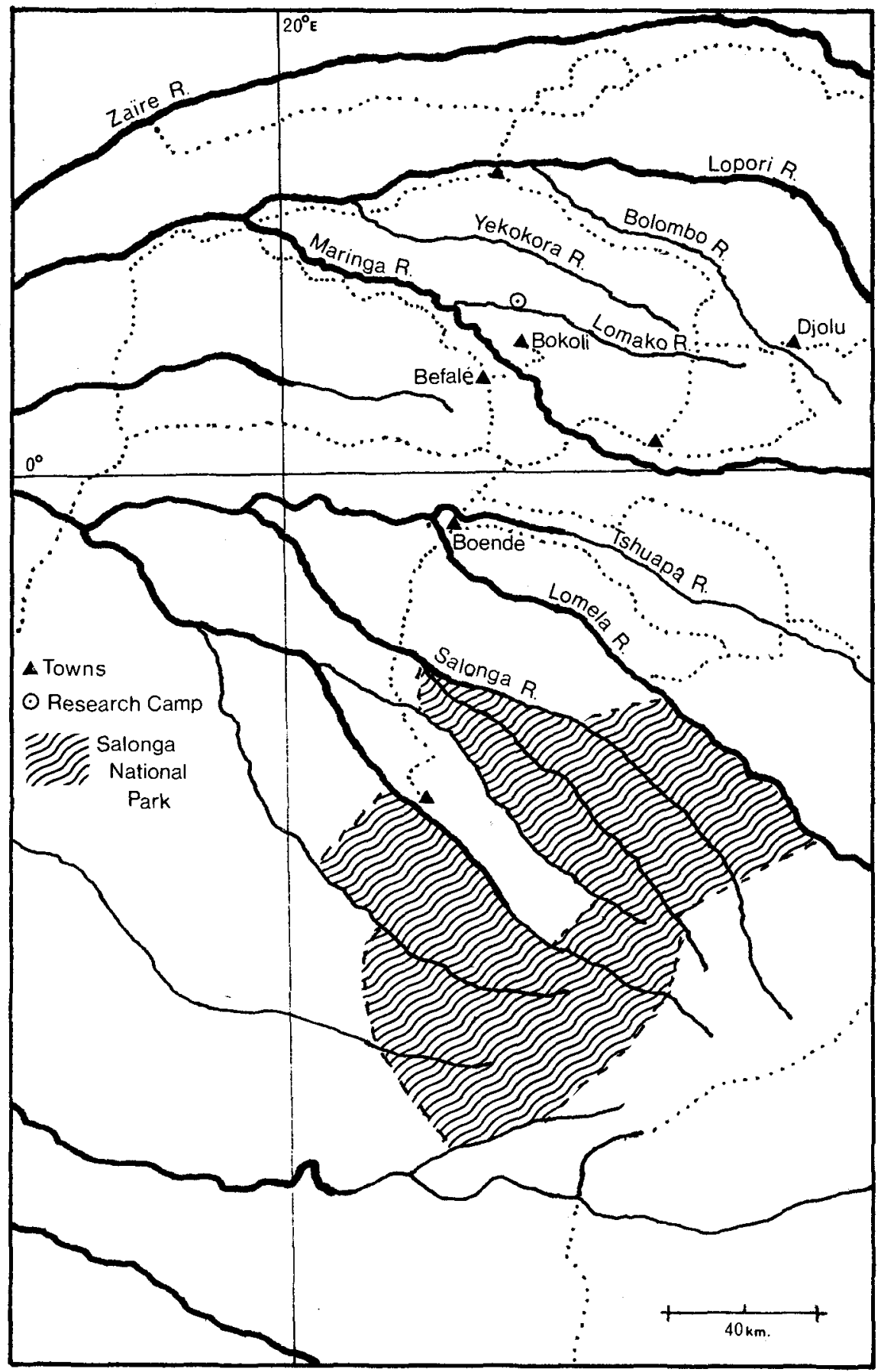

Main road/river system, Central Basin, Zaire 


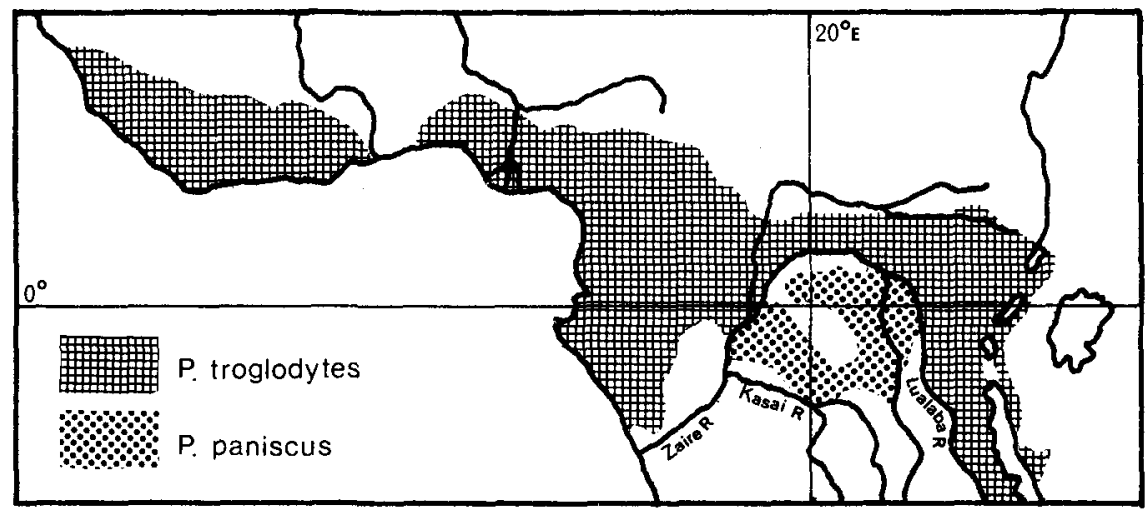

Distribution of the Genus Pan, after Reynolds 1965

captive chimpanzees, ${ }^{5,6}$ gentler, more intelligent and more nervous. When Hellabrunn Zoo was bombed in the last war the bonobo colony died of fright while a nearby group of chimpanzees were virtually unaffected. ${ }^{10}$ According to the 1976 International Zoo Year Book there are 28 bonobos in captivity -10 males and 18 females in seven collections.

In the wild, bonobos occur only in the tropical rain forest of Zaire, which is enclosed by the Zaire-Lualaba and Kasai rivers. We had intended to study them in the Salonga National Park, which was created partly to protect this ape, but in Boende we were told that a team of Japanese primatologists had found no trace of bonobos there, ${ }^{4}$ and the park conservator said the same. So, on the advice of a local naturalist, we looked for a study site in primary forest, because this must have been the bonobo's original habitat, north of Boende. We found it between the Lomako and Yekokora rivers, a remote area not permanently inhabited and said to contain both bonobos and a great variety of other animals.

The Lomako river banks are lined with extensive permanently flooded swamp forest, behind which is primary forest on firm, sandy soil. Trees up to 50 metres high form a closed canopy, and there are patches of secondary forest, the sites of long-abandoned villages, especially near streams. Most of the forest in our study area of about $35 \mathrm{sq} \mathrm{km}$ was easy to travel through as the herbaceous layer was usually poorly developed, but in the complex maze of animal paths in the flat, featureless terrain it was easy to become disorientated. Elephant Loxodonta africana, red forest hog Potamochoerus porcus, water chevrotain Hyemoschus aquaticus, sitatunga Tragelaphus spekei, porcupine Atherurus sp., civets Viverra civetta and Nandinia binotata, pangolins Manis spp., and several forest duikers Cephalophus spp. were some of the common animals, and every day we saw large mixed troops of monkeys black mangabeys Cercocebus aterrimus, mona Cercopithecus mona and redtailed monkeys $C$. ascanius - often with small groups of Angolan black and white colobus Colobus angolensis in their vicinity.

We spent over eight months in the Equateur region, of which 185 days was in the study area. From the start the bonobos were difficult to locate. The groups were small - about 80 per cent of our observations involved from one to four individuals - and travelled mostly on the ground, where they moved swiftly and silently. Unlike chimpanzees, which can be easily located by their 
loud calls, ${ }^{8}$ bonobos are conspicuously silent; also the intensity of their calls was much lower and their calling bouts far shorter than those of chimpanzees we had heard in the Gombe National Park in Tanzania, and in the dense flat rain forest even the loudest of their vocalisations (which differ greatly from chimpanzee calls) were inaudible less than a kilometre away. In the thick vegetation we often had to get underneath the animals before we could see them clearly. Moreover, although not hunted for food in our study area, they were extremely shy of humans, and excelled at hiding in the trees and sneaking away quietly when they saw us. Nevertheless, we collected some interesting data, many of which pointed to a number of differences between bonobos and chimpanzees, notably in locomotion, nest-building and feeding. ${ }^{2}$

The bonobos appeared to be more arboreal than chimpanzees, in that they sometimes travelled for more than a kilometre through the trees from one food source to another, whereas Jane van Lawick-Goodall found that chimpanzees seldom travelled more than two hundred yards through the trees. Sometimes if we frightened them they moved off through the trees rather than descending at once to the ground. Nest construction was similar, but the bonobos built at a greater average height than forest-dwelling chimpanzees. ${ }^{8}$ of the 26 tree species represented in Figure 1, 19 were recorded food trees; in fact 21 per cent of nests were in trees bearing fruit or leaves ready for eating. We quite often found bonobos feeding in a tree in the afternoon and nesting in it that night.

Their diet was mainly vegetarian but they also ate some animal food, and there is good evidence that they eat fish. ${ }^{4}$ We did not observe them 'fishing' Height of bonobo nests in the study area

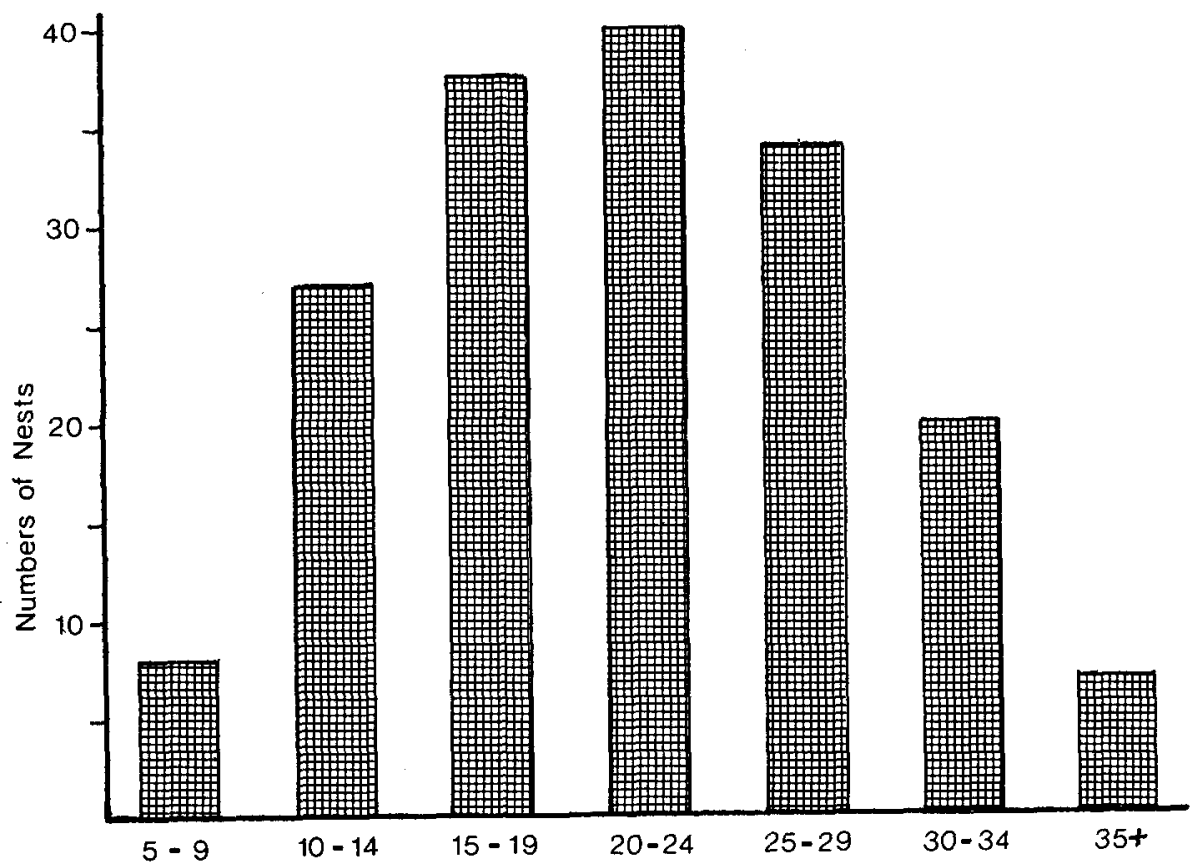

Nest Height in Meters 


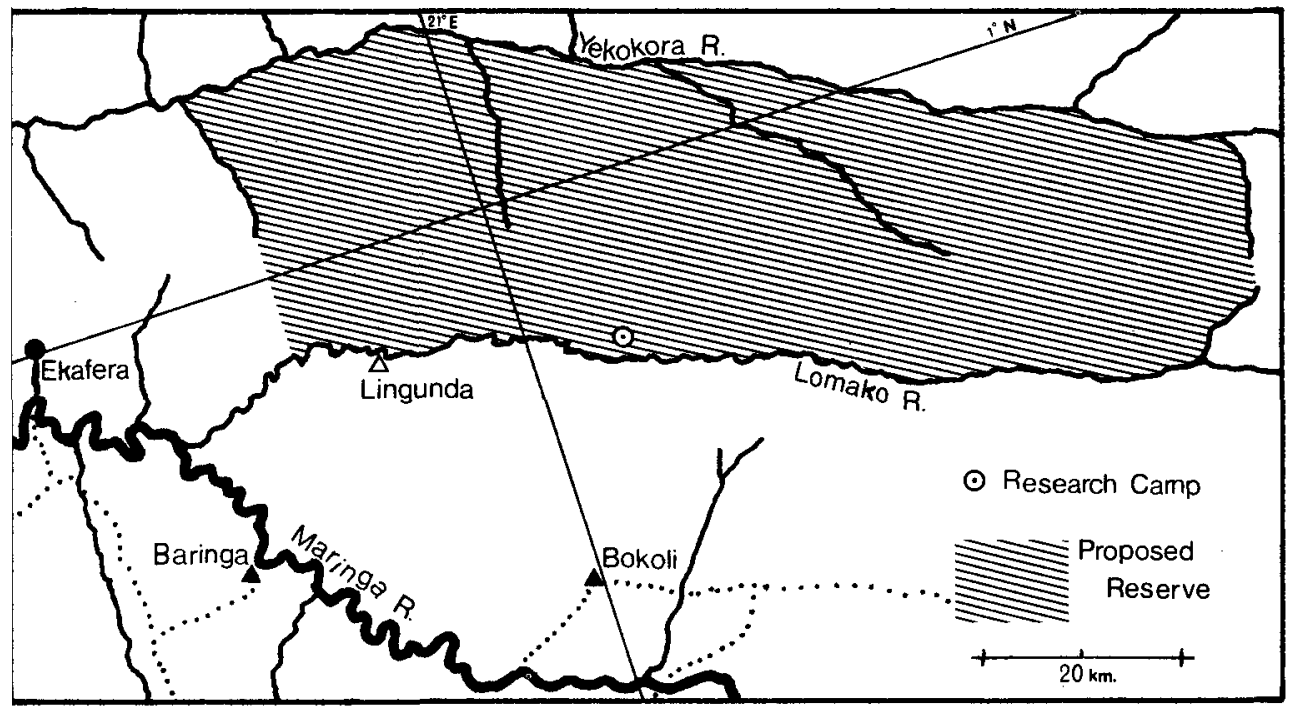

Area for proposed bonobo research centre and reserve

but bonobo footprints on a sand-bar in the middle of a wide, shallow stream showed that they had walked about 100 metres in the water, so they do not have the chimpanzees' strong aversion to walking through water. ${ }^{8}$ Between March and May, when fruit was not abundant, we frequently found in their faeces the remains of giant black millipedes and also vertebrate remains, including the complete lower jaw bones of a shrew and the dorsal and ventral scales of a small snake.

\section{Conservation}

At present the bonobos' status in the wild is controversial and there is little quantitative information. Their potential range is relatively large, but our enquiries indicated that their distribution is discontinuous and that isolated populations occur in sometimes widely separated areas. Much of the Salonga National Park does not appear to contain bonobos (compare maps 1 and 2), although the habitat seems suitable. A comprehensive distribution survey is urgently needed, but the bad roads, difficulty of obtaining supplies, and problems locating the bonobos will make it a long and costly undertaking.

Bonobos are fully protected in Zaire, but the law was not often enforced where we were. Some protected species are regularly killed for food-Angolan black-and-white colobus, water chevrotain, yellow-backed duiker and forest elephant, as well as bonobos. Hunting by traditional methods, such as bow and arrow, did little damage, but the increasing use of firearms, particularly shot-guns, is depleting animal populations at an alarming rate, and forests near towns are almost completely devoid of game, especially primates. We have seen a hunter return from a single day's shooting with over 20 monkey carcasses. Bonobos are also killed to make charms which are believed to confer strength and vigour on the wearer. Young bonobos are captured by killing the mother, and kept as pets or presented to visiting dignitaries.

Habitat destruction is an even more direct threat. The widely practised subsistence agriculture destroys large areas of primary forest, and near towns and villages forests are felled to provide wood for houses, canoes, and firewood. Moreover, a Canadian-Zairean cooperative venture has recently 
started a forest inventory which involves cutting wide transects through hitherto undisturbed forest, and may result in wholesale exploitation of the rain-forest belt for timber.

These facts provide strong grounds for establishing a bonobo reserve in conjunction with a field research centre, which could be funded internationally and involve overseas workers. The presence of a research centre would also help to deter poachers. We believe that the ideal site for such a reserve would be the strip of forest between the Lomako and Yekokora rivers:

1. The area is uninhabited but rich in wildlife, including bonobos. The people from Bokole and neighbouring villages, who cross the Lomako to fish and hunt, living in temporary camps, could be allowed to continue their traditional hunting, thus ensuring their cooperation; those who hunted in our study area did not eat bonobos and seldom killed monkeys.

2. The Lomako forest is fairly inaccessible. As neither the Lomako nor the Yekokora rivers is navigable by large boats, and road-making would be difficult, this part of the forest is not likely to be exploited for timber or other commercial crops, although a disused road between Bokole and an abandoned oil-palm plantation at Lingunda could be repaired and used for access to the reserve.

3. The Lomako and Yekokora rivers would form the reserve's north and south boundaries and could be patrolled by motorised canoes or small boats. The strips of disturbed forest between the two rivers and the roads on either side, where most hunting is done, would provide excellent buffer zones; all permanent habitation is along the roads.

4. The reserves should be about $3000 \mathrm{~km}$ - big enough to be viable yet small enough to be efficiently managed.

\section{Acknowledgments}

We would like to thank Miss A. Gusken who helped to finance our field study, the Poulton Fund and the Boise Fund for contributing to our maintenance while writing up our data. We are grateful to the INCN, and particularly to Dr Kabala and Dr Verschuren, for their advice and cooperation, and to Père P. Lootens, M.F. Christiaans, and the members of the Zaire-Canada Inventaire Forestier for their hospitality. Finally we thank our guides and helpers from the village of Bokole.

\section{References}

1. ANON., 1975. Consensus of rare animals in captivity. Int. Zoo. Yb. 16.

2. BADRIAN, A. \& BADRIAN, N., in prep. A preliminary field study on the ecology and behaviour of the bonobo Pan paniscus in the Lomako Forest, Zaire.

3. COOLIDGE, H.J., 1933. Pan paniscus. Pigmy chimpanzee from south of the Congo River. Am. J. Phys. Anthrop. 8 1: 1-57.

4. KANO, T., 1974. A pilot study on the ecology of pygmy chimpanzees, Pan paniscus. Unpublished report.

5. PALMANS, M., 1956. Un chimpanzé pas comme les autres. Zoo. Anvers, 21 : 30-84.

6. REMPE, U., 1961. Einige Beobachtungen an Bonobos, Pan paniscus. Z.f. Wiss. Zool. 165: $81-87$.

7. REYNOLDS, V., 1965. Some behavioural comparisons between the chimpanzee and the mountain gorilla in the wild. Am. Anthrop. 67 3:691-706.

8. REYNOLDS, V. \& REYNOLDS, F., 1965. Chimpanzees of the Budongo Forest. In Primate Behaviour (ed. I. DeVore). New York: Holt, Rinehart \& Winston.

9. SCHWARZ, E., 1929. Das Vorkommen des Schimpansen auf den linken Kongo-Ufer. Rev. Zool. Bot. Afr., 16 4: 425-433.

10. TRATZ, E. \& HECK, H., 1954. Der Africanisch Antropoide "Bonobo", eine neue Menschenaffengattung. Saugetierk. Mitt., 2: 97-101.

11. VAN LAWICK-GOODALL, J., 1968. The behaviour of free-living chimpanzees in the Gombe Stream Reserve. Anim. Behav. Monogr., 13 : 161-311.

A \& N Badrian, P.O. Box 1291, Ndola, Zambia; 35 South Hill, Dartry, Dublin 6, Eire. 